Journal of Engineering and Applied Sciences 15 (3): 762-772, 2020

ISSN: 1816-949X

(C) Medwell Journals, 2020

\title{
Flow and Thermal Mechanisms in Receiver Tube of Parabolic Trough Collectors with Rings Axially Connected Together and Radially Connected to the Inner Tube Surface
}

\author{
${ }^{1,2}$ Ali Jaber Abdulhamed, ${ }^{1}$ Nor Mariah Adam, ${ }^{3}$ Mohd Zainal Abidin Ab-Kadir and \\ ${ }^{3}$ Abdul Aziz Hairuddin \\ ${ }^{1}$ Department of Mechanical Engineering, Faculty of Engineering, University Putra Malaysia, \\ 43400 Serdang, Selangor, Malaysia, \\ ${ }^{2}$ Department of Automotive, College of Engineering AL-Musaib, University of Babylon, \\ Hilla, Babylon, Iraq \\ ${ }^{3}$ Department of Electrical and Electronic Engineering, Faculty of Engineering, \\ University Putra Malaysia, 43400 Serdang, Selangor, Malaysia
}

\begin{abstract}
Artificial obstructions on the underside of receiver tubes can increase the heat transfer coefficient between the receiver tubes (Heat Exchanger, HX) of Parabolic Trough Collectors (PTCs) and water as a working fluid. In this study, we numerically and experimentally tested the behavior of laminar mixed convective heat transfer in HX tube installed with baffles. These baffles are rings that are connected together axially and connected radially to the inner tube surface. Using ANSYS fluent Version 15.0, we performed computation fluid dynamics modeling to achieve heat transfer enhancement in HX tubes equipped with turbulator baffles under laminar flow conditions. Moreover, the effects of Pitch ratio (P/D) = 3, 6 and 10 and Reynolds number $\mathrm{Re} \leq 480$ were recorded. The novel application of the rings that are connected axially together and radially to the inner tube surface contributes to the long-term storage of thermal energy and promotes heat transfer via. conduction from the tube surface to the center line of the water flow within a short period. In the study, the baffles generated a vortex to increase the Nusselt number $(\mathrm{Nu})$ inside the $\mathrm{HX}$. To simulate heat flux, we calculated the constant wall heat flux of the receiver tube using an electric heater. Results indicated that using 20 rings as baffles instead of plain tubes improves heat transfer by up to 75\%. As P/D decreased and re increased, the heat transfer rate, friction factor (f) and Thermal Enhancement Factor (TEF) increased.
\end{abstract}

Key words: Thermal mechanism, receiver tube, ring baffles inserted, parabolic trough collector, flow mechanism, generated

\section{INTRODUCTION}

The turbulence and convective heat transfer in Heat Exchangers (HX) are typically improved by using flow obstructions such as baffles, wire coils and twisted tapes as tube/channel inserts. The characteristics of heat transfer and flow friction should be considered in assessing the thermal performance of $\mathrm{HX}$ equipped with turbulators. The characteristics of heat transfer and pressure drop are known to be dependent on the shapes and geometries of turbulators (Kongkaitpaiboon et al., 2010; Seemawute and Eiamsa-Ard, 2010; Naphon and Suchana, 2011; Eiamsa-Ard et al., 2009, 2010; Guo et al., 2011; Shivalingaswamy and Narahari, 2014; Maradiya et al., 2017; Liu et al., 2018). Liu et al. (2018) reported the changes in the heat transfer and flow resistance behavior in a circular tube fitted with multiple conical strips. They found that flow resistance and heat transfer rate increase as pitch decreases and as the number of conical strips increases (Liu et al., 2018). Zhang and Wang (2016) generated a vortex by inserting rectangular wings into a rectangle duct and later revealed that heat transfer can significantly increase with a rise in the rectangular winglet pair on the bottom wall of a channel. Acir and Ata (2016) enhanced the heat transfer in a solar air heater with circular turbulators and indicated that heat transfer rate, thermal performance factor and pressure loss tend to increase with a decrease in angle and Pitch ratio (P/D). Rivier et al. (2015) studied the effects of the insertion of $45^{\circ}$ or $60^{\circ}$ elliptical turbulators into HX tubes with different diameter ratios on heat transfer enhancement and pressure drop. They found that tubes equipped with turbulators at a curve angle of $45^{\circ}$ experience increased heat transfer of up to $900 \%$ relative to the heat transfer of plain tubes. Abdollahi and Shams (2015) reported the influence of vortex generators such as trapezoidal, rectangular and delta vortex generators on heat transfer behavior. The study showed that rectangular vortex generators achieve the highest heat transfer and pressure drop because of their large areas facing the flow. 


\section{J. Eng. Applied Sci., 15 (3): 762-772, 2020}
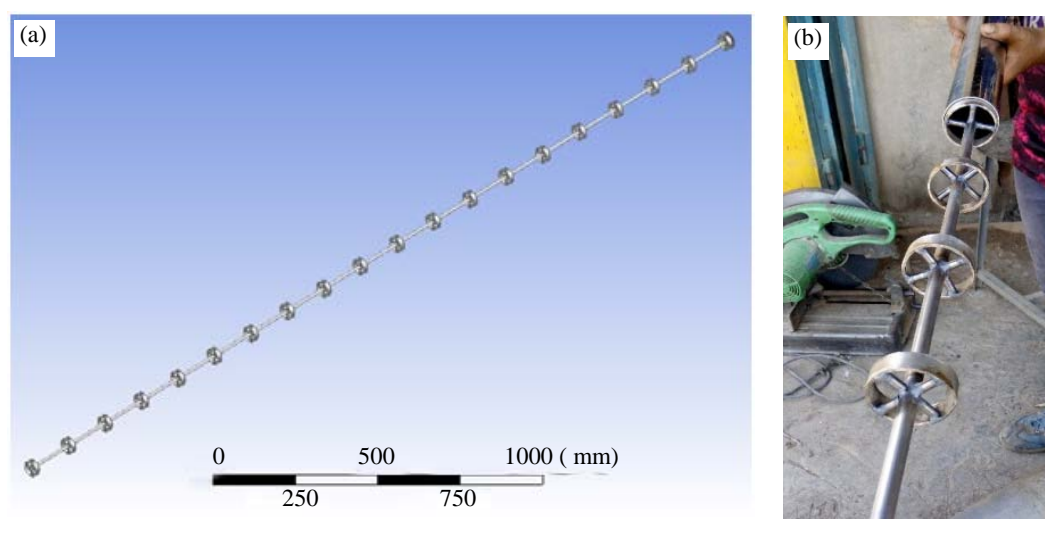

Fig. 1(a-b): Baffles geometry (a) Schematic of ring baffles and (b) Fabricate tube fitted with ring baffles

Gholami et al. (2014) studied the effects of using wavy-up and wavy-down rectangular winglets in fin-and-tube compact HX on the improvement of heat transfer. Wavy rectangular winglets were found to reduce pressure drop and significantly increase heat transfer. Sadeghi et al. (2016) numerically investigated the effects of tubes equipped with helical tapes at different twist ratios on heat transfer augmentation. They successfully increased the heat transfer rate by reducing the tape-twist ratio. Oni and Paul (2016) utilized the RNG k-e turbulence model in their numerical study of convective heat transfer in tubes inserted with triangular cut twisted tapes with alternating axes under various tape pitches and widths. The thermal performance of the tube with such insert was found to be greater than that of a plain tube. Saravanan et al. (2016) utilized a solar water heater equipped with a helix twisted tape with a V cut and a helix twisted tape with a square cut as they experimentally studied the changes in heat transfer and friction factors. The heat transfer and friction factor of the solar water heater equipped with a helix twisted tape with a V cut were better than those of the solar water heater with a helix twisted tape with a square cut. Zhang and Wang (2016) performed a numerical simulation to study the effects of longitudinal vortices on the heat transfer enhancement of a laminar flow in a rectangle duct with a rectangular winglet pair on thebottom wall. Diwan and Soni (2015) studied pressure drops and heat transfer behavior using a tube fitted with wire coil inserts. The turbulence inside the tube increased when the wire coils were inserted and the Nusselt number $(\mathrm{Nu})$ increased from 104-330\%. Kongkaitpaiboon et al. (2010) experimentally studied the effects of a circular-ring turbulator with $\mathrm{P} / \mathrm{D}$ values ranging from 6-12 on the heat transfer and fluid friction characteristics of tubes. The heat transfer rates in the tube fitted with a circular insert improved by around 57-195\% relative to the plain tube, especially when the P/D declined.

The literature review indicates that heat transfer conditions can be enhanced by using obstruction geometry as devices for enhancing heat transfer. The current study explored the flow and heat transfer behavior in tubes equipped with baffles under P/D = 3, 6 and 10 . These baffles are rings connected axially to one another and radially to the inner surface of an HX tube. The study achieved a laminar mixed convection flow with Reynolds numbers $\operatorname{Re} \leq 480$. This study describes the numerical simulation of the fluid structure and thermal phenomena in HX tubes equipped with baffle turbulators to improve our understanding of heat transfer mechanisms.

Design description: Figure 1 a, b and 2, respectively present the image and detailed diagram of the receiver tube equipped with baffle turbulators.

To test the influence of shape geometry and number of baffles on flow structure, pressure loss, mechanism of heat transfer and behaviors of thermal performance augmentation in a uniform wall heat flux tube, we prepared a baffle turbulator in a tube under $\mathrm{P} / \mathrm{D}=3,6$ and 10 . The ring width, axial connecting tube diameter and cross tube diameter were 15, 10 and $6 \mathrm{~mm}$, respectively. Fig. 1 shows the obstruction structure insert in the $3000 \mathrm{~mm}$ receiver tube for testing. The receiver tube and baffle turbulator are made from stainless steel.

Experimental equipment and procedure: Figure $3 \mathrm{a}$, b shows the experimental equipment and the test tube equipped with baffle turbulators with different P/D. The experimental model comprised a water source from the city pipe line an orifice flow meter for measuring the rate of volumetric water flow, pressure gauges for measuring pressure loss, a test tube with baffle turbulators and 15 type-K thermocouples soldered in grooves along the test wall of the stainless steel tube for recording the local Temperature $\left(T_{w}\right)$ of the tube wall. Seven type-K thermocouples were soldered at different points on the axial tube in the center line of flow inside the HX tube for temperature measurement. The obtained temperature was then compared with the center line temperature of a plain 
(a)

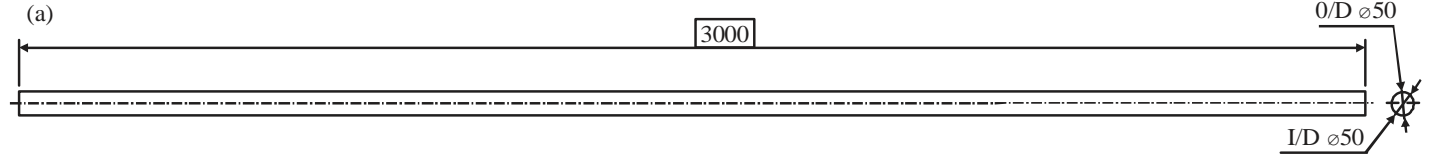

(b)
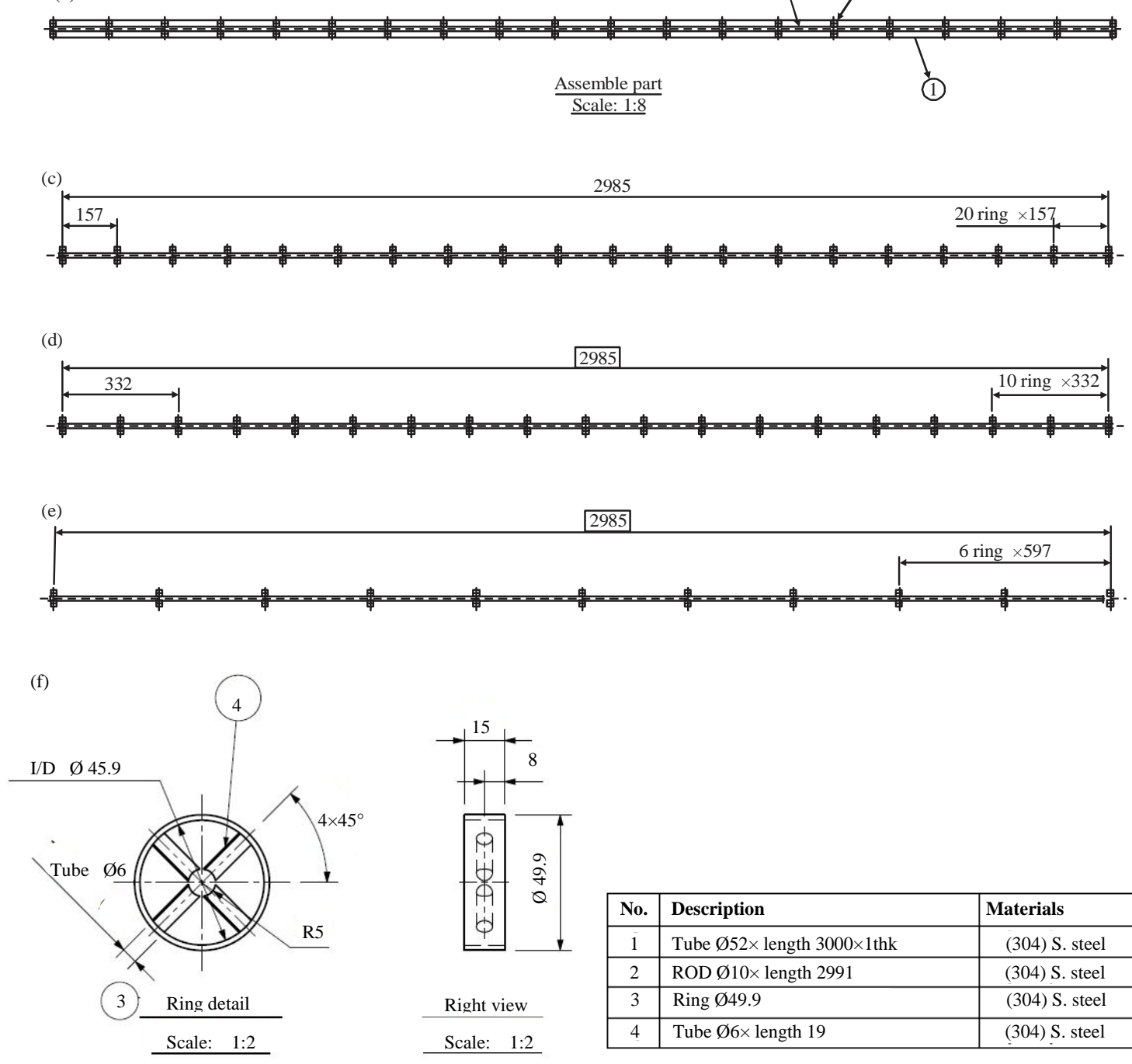

\begin{tabular}{|c|l|c|}
\hline No. & Description & Materials \\
\hline 1 & Tube $\varnothing 52 \times$ length $3000 \times 1$ thk & $(304)$ S. steel \\
\hline 2 & ROD $\varnothing 10 \times$ length 2991 & $(304)$ S. steel \\
\hline 3 & Ring Ø49.9 & $(304)$ S. steel \\
\hline 4 & Tube Ø6× length 19 & $(304)$ S. steel \\
\hline
\end{tabular}

Fig. 2(a-f): Schematic of receiver tube fitted with baffles with whole dimensions (a) Receiver tube (b) Assembly parts, tube and baffles (c) Rod with 20 rings (d) Rod with 10 rings (e) Rod with 6 rings and (f) Ring dimensions

tube. The experimental model also included a Resistance Temperature Detector (RTD) for measuring the water temperature at the entrance and exit of the HX tube, a data logger for recording wall and fluid temperatures, a flexible electrical wire heater for simulating heat flux, a multi-meter for recording the inlet power supply, a variance transformer for controlling a heater and a personal computer. The test tube with baffle turbulators is shown in Fig. 3, along with the locations of the pressure gauge, temperature sensors, RTDs and orifice flow meter.
The receiver tube measured $3 \mathrm{~m}$ in Length (L) and was made from 304 stainless steel with a thickness of $2 \mathrm{~mm}$, inner Diameter $\left(D_{i}\right)$ of 0.05 and outer Diameter $\left(D_{0}\right)$ of $0.052 \mathrm{~m}$ (Fig. 2). The test tube was coiled with a flexible electrical wire which served as the heater. The tube was insulated lengthwise and externally to avoid heat loss. The heater was controlled by the AC power supply serving as a variance transformer to provide a Uniform Heat Flux (UHF) condition on the wall. The local wall Temperatures $\left(T_{w}\right)$ recorded at the same axial distance but different 

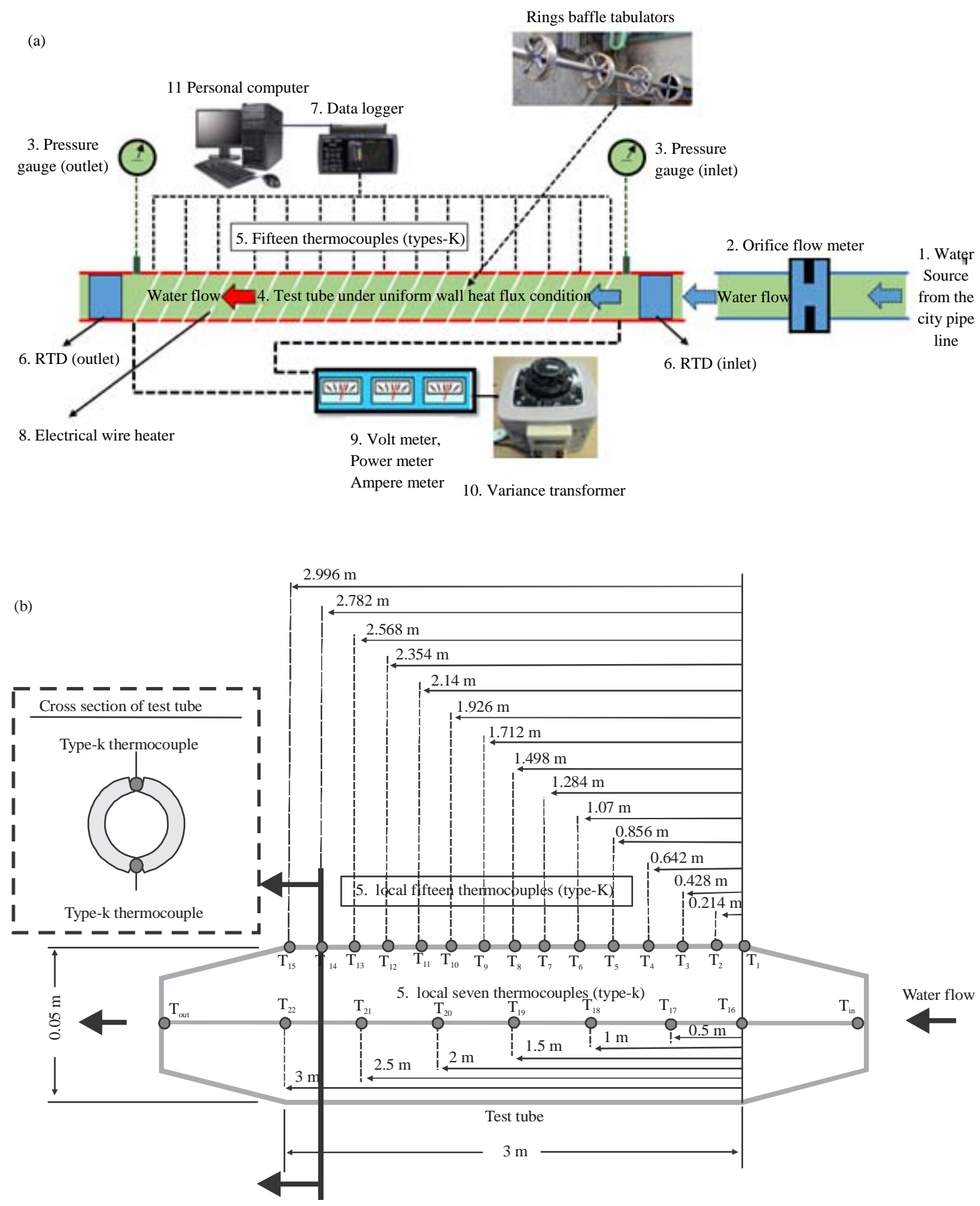

Fig. 3(a-b): Facility of the present investigation (a) Diagram of heat transfer experiment setup and (b) Test tube details

circumferential positions were comparable. Two RTDs recorded the water temperatures in the inlet and outlet. These RTDs were located at the center of the inlet and outlet tube core. The thermocouples were soldered in a groove located on the outer wall of each point at a groove depth of $0.4 \mathrm{~mm}$. The soldered thermocouples were provided with high-temperature silicon insulation to prevent their direct exposure to the heater. The experimental data including the bulk fluid and wall temperatures were measured under steady state conditions. 


\section{MATERIALS AND METHODS}

Nunerical method: In this study, the fluid is incompressible and exhibits constant thermo-physical properties. The receiver tube of the $\mathrm{HX}$ is assumed to be in a 3D laminar and steady state given the low water inlet velocity. Meanwhile, the tube surface is set under heat flux conditions. The mass continuity equation, momentum equations in the axial and radial directions and energy equations of the liquid and the solid material of the tube serve as the governing equations in the tube. The governing equations of continuity, momentum and energy for fluid flow are written respectively as continuity equation:

$$
\frac{\partial \rho}{\partial t}+\frac{\partial(\rho . u)}{\partial x}+\frac{1}{r} \frac{\partial(\rho . v . r)}{\partial r}=0
$$

Momentum equation:

$$
\frac{\partial\left(\rho_{\mathrm{L}} \cdot \mathrm{u}\right)}{\partial \mathrm{t}}+\frac{\partial\left(\rho_{\mathrm{L}} \cdot \mathrm{u}^{2}\right)}{\partial \mathrm{x}}+\frac{1}{\mathrm{r}} \frac{\partial\left(\rho_{\mathrm{L}} \cdot \mathrm{v} \cdot \mathrm{r} \cdot \mathrm{u}\right)}{\partial \mathrm{r}}=\frac{\partial}{\partial \mathrm{x}}\left(\mu \cdot \frac{\partial \mathrm{u}}{\partial \mathrm{x}}\right)+\frac{1}{\mathrm{r}} \frac{\partial}{\partial \mathrm{r}}\left(\mu \cdot \mathrm{r} \cdot \frac{\partial \mathrm{u}}{\partial \mathrm{r}}\right)-\frac{\partial \mathrm{P}}{\partial \mathrm{x}}
$$

Energy equation:

$$
\frac{\partial\left(\rho_{\mathrm{L}} \cdot \mathrm{v}\right)}{\partial \mathrm{t}}+\frac{\partial\left(\rho_{\mathrm{L}} \cdot \mathrm{u} \cdot \mathrm{v}\right)}{\partial \mathrm{x}}+\frac{1}{\mathrm{r}} \frac{\partial\left(\rho_{\mathrm{L}} \cdot \mathrm{r} \cdot \mathrm{v}^{2}\right)}{\partial \mathrm{r}}=\frac{\partial}{\partial \mathrm{x}}\left(\mu \cdot \frac{\partial \mathrm{u}}{\partial \mathrm{x}}\right)+\frac{1}{\mathrm{r}} \frac{\partial}{\partial \mathrm{r}}\left(\mu \cdot \mathrm{r} \cdot \frac{\partial \mathrm{v}}{\partial \mathrm{r}}\right)-\frac{\partial \mathrm{P}}{\partial \mathrm{r}}
$$

Fluid enthalpy $\left(\mathrm{Cp}_{\mathrm{L}} \cdot \mathrm{T}\right)$ is considered as an additional energy equation for the solid material of the receiver tube:

$$
\frac{\partial\left(\rho_{\mathrm{L}} \cdot \mathrm{Cp} \mathrm{p}_{\mathrm{L}} \cdot \mathrm{T}\right)}{\partial \mathrm{t}}+\frac{\partial\left(\rho_{\mathrm{L}} \cdot \mathrm{u} \cdot \mathrm{C} \mathrm{p}_{\mathrm{L}} \cdot \mathrm{T}\right)}{\partial \mathrm{x}}+\frac{1}{\mathrm{r}} \frac{\partial\left(\rho_{\mathrm{L}} \cdot \mathrm{r} \cdot \mathrm{v} \cdot \mathrm{Cp}_{\mathrm{L}} \cdot \mathrm{T}\right)}{\partial \mathrm{r}}=\frac{\partial}{\partial \mathrm{x}}\left(\mathrm{k}_{\mathrm{L}} \cdot \frac{\partial \mathrm{T}}{\partial \mathrm{x}}\right)+\frac{1}{\mathrm{r}} \frac{\partial}{\partial \mathrm{r}}\left(\mathrm{k}_{\mathrm{L}} \cdot \mathrm{r} \frac{\partial \mathrm{T}}{\partial \mathrm{r}}\right)
$$

$$
\frac{\partial\left(\rho_{\mathrm{s}} \cdot \mathrm{Cp}_{\mathrm{s}} \cdot \mathrm{T}\right)}{\partial \mathrm{t}}=\frac{\partial}{\partial \mathrm{x}}\left(\mathrm{k}_{\mathrm{s}} \cdot \frac{\partial \mathrm{T}}{\partial \mathrm{x}}\right)+\frac{1}{\mathrm{r}} \frac{\partial}{\partial \mathrm{r}}\left(\mathrm{k}_{\mathrm{s}} \cdot \mathrm{r} \cdot \frac{\partial \mathrm{T}}{\partial \mathrm{r}}\right)
$$

Equation 5 is the additional energy equation in the improved numerical model. This equation is used to consider the effects of the solid material at different lengths of the receiver tube.

The Computational Fluid Dynamics (CFD) Software Fluent 15.0 is used to solve the governing equations. The software is based on the finite volume method. The SIMPLE algorithm is adopted to derive a solution for the coupling between pressure and velocity. The assumptions applied in the present study are as follows:
- The flow is under steady state conditions at $R e=460$

- The tube wall is under constant wall heat flux conditions at $1500\left(\mathrm{Wm}^{-2}\right)$

- The physical properties of water are assumed constant according to the mean bulk Temperature $\left(\mathrm{T}_{\mathrm{b}}\right)$

- As a function of water average (bulk) Temperature $\left(T_{\text {ave }}\right)$ in $\mathrm{K}$, the physical properties of water (p, $\mu, \mathrm{k}$ ) are uniform in space and updated in time in the formulation of the mathematical model

\section{Density in $\left(\mathrm{kgm}^{-3}\right)$ :}

$$
\rho=863+1.21\left(\mathrm{~T}_{\text {ave }}\right)-0.00257\left(\mathrm{~T}_{\text {ave. }}\right)^{2}
$$

Dynamic viscosity in $(\mathrm{kg} / \mathrm{msec})$ :

$$
\mu=0.0007\left(\frac{T_{\text {ave. }}}{315}\right)^{-5.5}
$$

Thermal conductivity in (W/mk):

$$
\mathrm{k}=0.375+8.84 \times 10^{-4}\left(\mathrm{~T}_{\text {ave. }}\right)
$$

Figure 4 presents the grid system generated by the meshing of hexahedral elements in the wall of the absorber tube via. the ring vortex technique for the generation of the mesh domain. The reliability of the simulation results is enhanced by employing unstructured grids around the tubes and vortex generators.

This study evaluates mesh quality which includes the number of elements, number of nodes, maximum aspect ratio, maximum skewness and minimum orthogonal quality of the cells. The number of mesh elements is based on the orientation, size and spacing of the insert. In this study, the number of mesh elements reaches 2, 290, 981. The solution is considered converged when the scaled residuals of continuity, momentum and energy remain constant after approximately 144 successive iterations. The minimum values of the scaled residuals after these iterations equate $\left(10^{-3}\right)$ to for the continuity equation and the velocity and laminar quantities. The values equate to $\left(10^{-6}\right)$ for the energy equation.

Experimental data analysis: The electrical wire used as a heater in the current study served as the heat energy source. We calculated the heating tube under constant surface heat flux as well as the heat transfer rate ( $\dot{q})$ written as Skullong et al. (2017):

$$
\mathrm{q}=\dot{\mathrm{m}}_{\mathrm{p}}\left(\mathrm{T}_{\text {out }}-\mathrm{T}_{\text {in }}\right)=\mathrm{VI}
$$



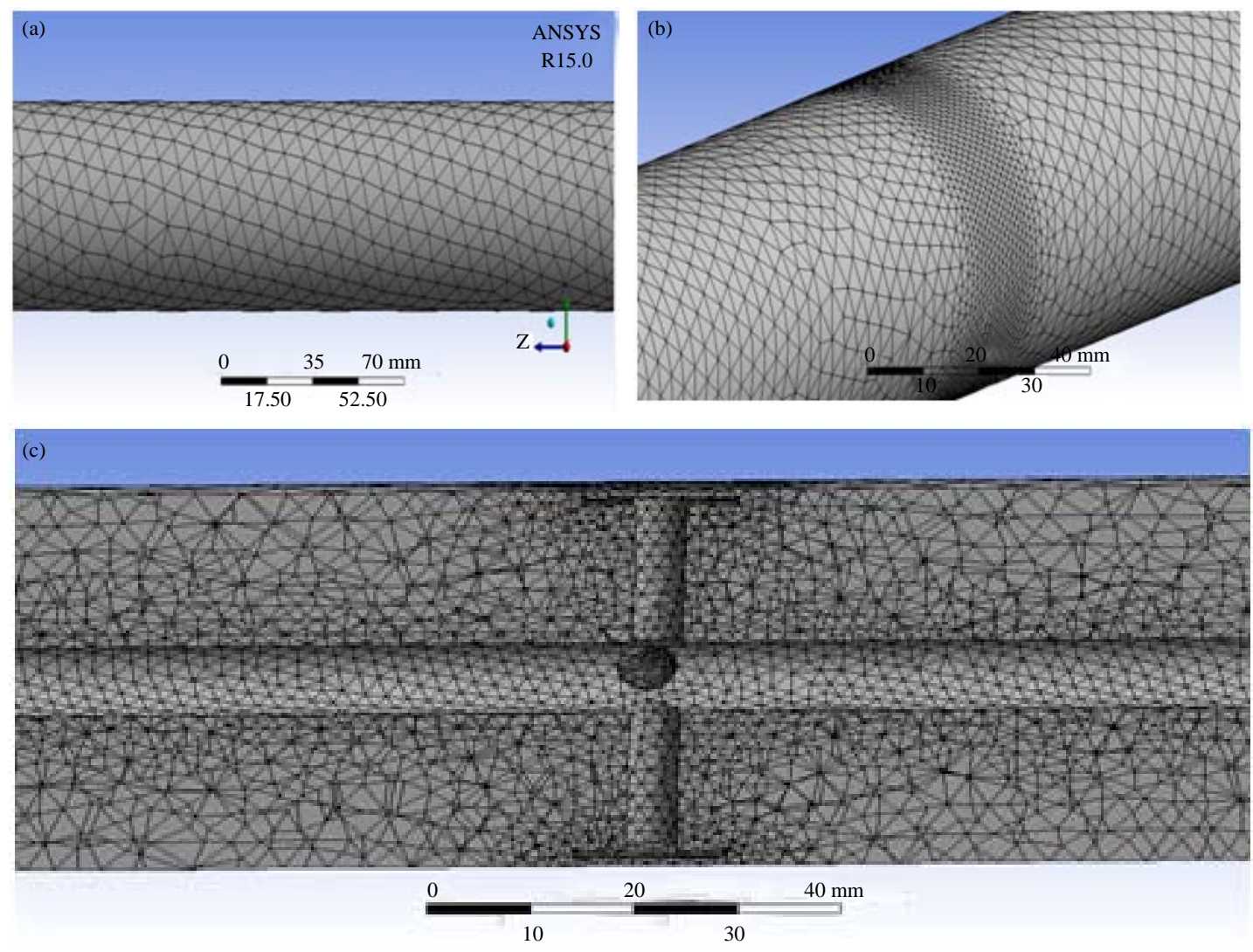

Fig. 4(a-c): Grids generated for the computation domain of the baffles (a) Smoothness of the mesh (Hexahedral element for plain tube) (b) Smoothness of the mesh (Hexahedral element for absorber tube with insert rings) and (c) Smoothness of the mesh (longitudinal section for absorber tube with Hexahedral element)

where, $\mathrm{T}_{- \text {in }} \mathrm{T}_{- \text {out }}, \mathrm{V}$ and I are the mean fluid temperature at the tube inlet, mean fluid temperature at the tube outlet, voltage and current, respectively ( $\dot{m})$ is the fluid mass flow rate through the tube. It can be estimated by m $=$ $\rho u(\pi / 4) D_{i}^{2}$ where $\rho$ and $u$ is the fluid density and velocity, respectively. The heat flux was estimated from heat transfer rate over the heat transfer surface area $(\mathrm{q} / \mathrm{A})$ of the heating tube (Skullong et al., 2016):

$$
\begin{gathered}
\mathrm{q}=\mathrm{h} \mathrm{A}\left(\tilde{\mathrm{T}}_{\text {wall }}-\mathrm{T}_{\text {bulk }}\right) \\
\tilde{\mathrm{T}}_{\text {wall }}=\sum\left(\mathrm{T}_{\mathrm{w} 1}+\mathrm{T}_{\mathrm{w} 2}+, \ldots,+\mathrm{T}_{\mathrm{w} 15}\right) / 15
\end{gathered}
$$

By substituting Eq. 9 into 10, we calculated the heat transfer coefficient as Skullong et al. (2017):

$$
\mathrm{h}=\frac{\dot{\mathrm{m}}_{\mathrm{p}}\left(\mathrm{T}_{\text {out }}-\mathrm{T}_{\text {in }}\right)}{\mathrm{h} \mathrm{A}\left(\mathrm{T}_{\text {wall }}-\mathrm{T}_{\text {bulk }}\right)}
$$

Then, we calculated Nu by Skullong et al. 2017):

$$
\mathrm{Nu}=\mathrm{h} \times \mathrm{Di} / \mathrm{k}
$$

The calculation of $\operatorname{Re}$ and friction factor $f$ is written as Liu et al. (2018) and Abduhamed et al., 2016):

$$
\begin{aligned}
& \mathrm{Re}=\mathrm{u} \times \mathrm{D}_{\mathrm{i}} / \mathrm{v} \\
& \mathrm{f}=\frac{(\Delta \mathrm{P} / \mathrm{L}) \mathrm{D}_{\mathrm{i}}}{\left(\rho \mathrm{u}^{2} / 2\right)}
\end{aligned}
$$

where, (u) is the mean fluid velocity, $(\mathrm{L})$ is the test tube length and $(\Delta \mathrm{P})$ is the pressure drop between the entry and the exit of the tube.

On the basis of the bulk temperature $\mathrm{Tb}=$ $\left(\mathrm{T}_{\text {in }}+\mathrm{T}_{\text {out }}\right) / 2$, we estimated the properties of water including the specific heat transfer $\left(\mathrm{C}_{\mathrm{p}}\right)$, thermal conductivity (k), density $(\rho)$ and kinetic viscosity (v). Two 
RTDs were used to record the fluid temperatures in the inlet and outlet. The RTDs were installed at the inlet and outlet upstream. According to Webb (1981), the Thermal Enhancement Factor (TEF) based on an equal Pumping Power (PP) can be used to evaluate the thermal performance of HX (Webb, 1981; Sara et al., 2000):

$$
\begin{gathered}
\mathrm{pp}_{\mathrm{p}}=\mathrm{pp} \\
(\dot{\mathrm{V}} \times \Delta \mathrm{P})_{\mathrm{p}}=(\dot{\mathrm{V}} \times \Delta \mathrm{P})
\end{gathered}
$$

Where:

$$
\begin{aligned}
\dot{\mathrm{V}} \text { and } \dot{\mathrm{V}}_{\mathrm{p}}: \begin{array}{l}
\text { The Volumetric flow rates in the } \\
\text { tubes with and without baffles, }
\end{array} \\
\text { respectively } \\
\Delta \mathrm{P} \text { and } \Delta \mathrm{P}_{\mathrm{p}}: \begin{array}{l}
\text { The corresponding pressure drops and the } \\
\text { subscript } \mathrm{p} \text { is the plain tube }
\end{array}
\end{aligned}
$$

Equation 17 is can be written by the relationship between friction factor $\mathrm{f}$ and $\mathrm{Re}$ as follows using the Darcy equation for pressure drop and (Sara et al., 2000; Skullong et al., 2015):

$$
\left(F \times \operatorname{Re}^{3}\right) p=\left(f \times \operatorname{Re}^{3}\right)
$$

We defined the TEF as the ratio of the heat transfer coefficient (h) of an enhanced tube to the heat transfer coefficient of a plain tube at the same pumping power $\left(\mathrm{h}_{\mathrm{p}}\right)$ (Skullong et al., 2015; Bilen et al., 2001):

$$
\begin{aligned}
& \mathrm{TEF}=\eta=\left.\left(\mathrm{h} / \mathrm{h}_{\mathrm{p}}\right)\right|_{\mathrm{pp}}=\left.\left(\mathrm{Nu} / \mathrm{Nu}_{\mathrm{p}}\right)\right|_{\mathrm{pp}}= \\
& \left(\mathrm{Nu} / \mathrm{Nu}_{\mathrm{p}}\right) \times\left(\mathrm{f} / \mathrm{f}_{\mathrm{p}}\right)^{-1 / 3}
\end{aligned}
$$

Where:

$\mathrm{Nu}$ : The Nusselt number

f : The friction factor of the test tube inserted with a baffle and the subscript

$\mathrm{p}$ : The plain tube

The analysis clearly highlighted the assumption that the fluid density remains constant across any cross section. A radial density gradient can be expected because of the presence of a radial temperature gradient. The radial density gradient tends to cause buoyancy motion. Given a large temperature difference or heat flux, the effects of natural convection cannot be neglected, therefore, the correlated mixed convection heat transfer results for the external and internal flows were expressed as (Bergman et al., 2011; Hieber, 1982; Li and Feng, 2013):

$$
\mathrm{Nu}^{\mathrm{n}}=\mathrm{Nu}_{\mathrm{F}}^{\mathrm{n}} \pm \mathrm{Nu}_{\mathrm{N}}^{\mathrm{n}}
$$

The Nusselt numbers $\left(\mathrm{Nu}_{\mathrm{f}}\right)$ and $\left(\mathrm{Nu}_{\mathrm{n}}\right)$ were estimated from the existing correlations of pure forced convection and natural convection, respectively, under specific flow and tubing conditions. The plus sign on the right side of Eq. 20 indicated assisting and transverse flows. The minus sign denoted the opposing flow. The plus sign was assigned to the fluid being heated in the horizontal tube. The best data correlation is often obtained when $\mathrm{n}=3$. The correlation form can be further written as ( $\mathrm{Li}$ and Feng, 2013; Oliver, 1962; Christiansen and Craig Jr, 1962):

$$
\begin{aligned}
& \left(\mathrm{Nu}\left(\mu_{\mathrm{w}} / \mu_{\mathrm{b}}\right)^{0.14}\right)^{3}=\left(\mathrm{A} \mathrm{Gz}^{1 / 3}\right)^{3}+ \\
& \left(\mathrm{A}\left(0.0083(\mathrm{Gr} \mathrm{Pr})^{0.75}\right)^{1 / 3}\right)^{3} \\
& \text { Overall Forced Normal }
\end{aligned}
$$

where, A is equal to 1.75 and 2.11 for the boundary conditions of the uniform wall temperature UWT and Uniform Heat Flux UHF, respectively. Thus, the correlation by Oliver (Li and Feng, 2013; Oliver, 1962; Christiansen and Craig Jr, 1962). Heat transfer to pseudoplasti is suggested for the laminar mixed convection under UHF.

$$
\mathrm{Nu}=2.11\left(\mu_{\mathrm{b}} / \mu_{\mathrm{w}}\right)^{0.14}\left[\begin{array}{l}
\mathrm{Gz}+0.0083 \\
(\mathrm{Gr} P r)^{0.75}
\end{array}\right]^{1 / 3}
$$

where, Gr is the dimensionless group called the Grashof number which is expressed as (Oliver, 1962):

$$
\mathrm{Gr}=\left[\mathrm{g} \beta\left(\mathrm{T}_{\mathrm{w}}-\mathrm{T}_{\infty}\right) \mathrm{D}^{3}\right] v^{2}
$$

The terms $\mu_{\mathrm{b}}$ and $\mu_{\mathrm{w}}$ is the dynamic viscosity at bulk and wall temperature, respectively $(\mathrm{Gr} \times \mathrm{Pr})$ is the dimensionless group called the Rayleigh number ( $\mathrm{Li}$ and Feng, 2013). The dimensionless group Graetz number $(\mathrm{Gz})$ is defined as:

$$
\mathrm{Gz}=\operatorname{Re} \times \operatorname{Pr} \times \mathrm{D} / \mathrm{L}
$$

where, Pr is Prandtl number

Validation test: To verify the experimental data, we validated the heat transfer rate ( $\mathrm{Nu}$ ) and pressure loss (f) results of the plain tube with those of the standard correlations by Oliver (1962) and McKeon et al. (2004) (Fig. $5 \mathrm{a}, \mathrm{b}$ ). Table 1 lists all the details of the validation. 

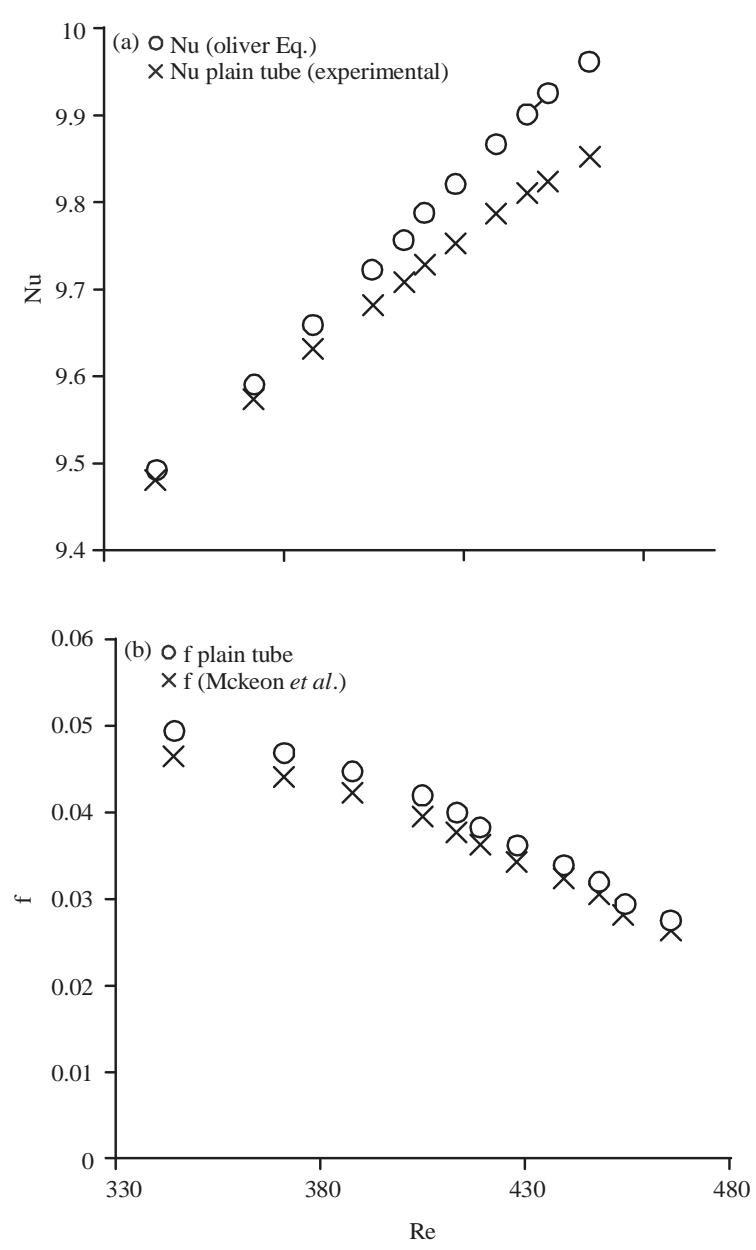

Fig. 5(a-b): Validation test of the plain tube without baffle inserts (a) $\mathrm{Nu}$ and (b) Friction factor

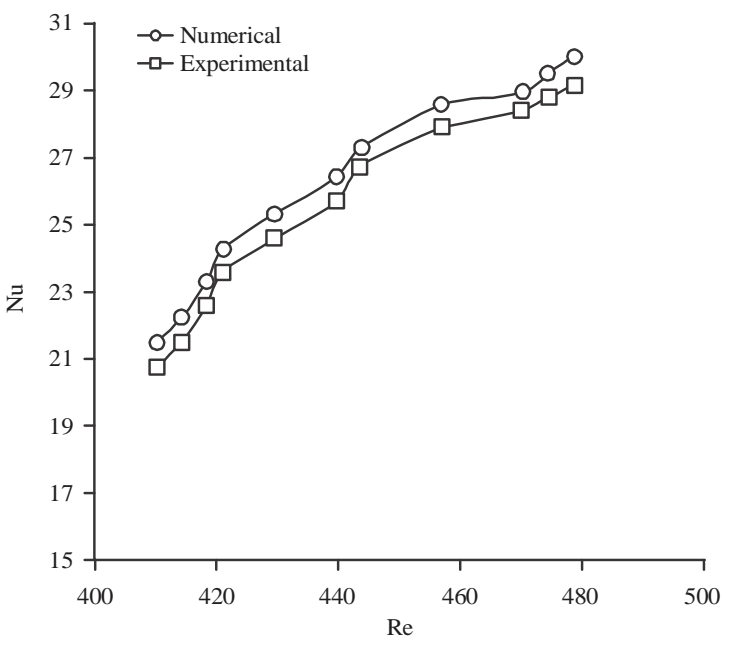

Fig. 6: Validation between numerical and experimental tests for a tube with $\mathrm{P} / \mathrm{D}=3$
Table 1: Details of experimental validation of the plain tube

\begin{tabular}{ll}
\multicolumn{1}{c}{ test } & \\
\hline Variables & Range \\
\hline Current through an electrical wire (A) & 6.8 \\
Entry temperature, $\mathrm{T}_{\text {inlet }}\left({ }^{\circ} \mathrm{C}\right)$ & 30 \\
Heat flux $\left(\mathrm{Wm}^{-2}\right)$, & 1500 \\
Inside diameter of test tube (m) & 0.05 \\
Mass flow rate, $\left(\mathrm{kg} \mathrm{sec}^{-1}\right)$ & 0.00000617 \\
Reynolds number test & $350-480$ \\
Test tube & Stainless steel \\
Fluid & Water \\
\hline
\end{tabular}

The resulting $\mathrm{Nu}$ values indicated a negative deviation from Oliver's correlation ranging from 3-5\%. The resulting friction factors were lower than those obtained by McKeon et al. (2004) by approximately 2.5-3\%. These deviations were insignificant and thus indicated the good reliability of the plain tube data. Therefore, the data can serve as reference for the performance evaluation of the tube with turbulators. The numerical results were validated by comparing them with the experimental data under the same operating conditions. The numerical and experimental results showed a good agreement. The maximum deviations of the Numerical $\mathrm{Nu}$ from the experimental data were within $3.5 \%$ for $\mathrm{P} / \mathrm{D}=3$ (Fig. 6).

\section{RESULTS AND DISCUSSION}

Flow and thermal mechanisms: We visualized the contours of the local temperature vectors of the tube with turbulators to understand the heat transfer distribution. Fig. 7a-c show the contours of the local temperature vectors of the tube with 6,10 and 20 baffles. Fig. 7d-f present the local temperature contours in the baffles with $P / D=10,6$ and 3 . The tubes inserted with 20 rings Fig. $7 \mathrm{a}$ and $\mathrm{d}$ showed more uniform and intense temperature distributions in the tubes compared with the tubes equipped with 10 and 6 rings Fig. 7b-f, respectively).

As shown in Fig. 8, the temperature intensity at the ring surface increased. The temperature of the ring structure transferred from the tube surface to the center line of fluid flow by conduction. Hence, the heat transfer in the fluid for the tube with rings was greater than that for the plain tube without baffles. Moreover, the temperature distribution in the 20-ring structure (Fig. 8 a) was more uniform and intense than that in the 10- and 6-ring structures (Fig. 8b, c), respectively). The surrounding of the baffle structure showed a high swirl flow. This swirl flow not only increased the $\mathrm{Nu}$ but also prevented the formation of hot spots on the tube wall. 

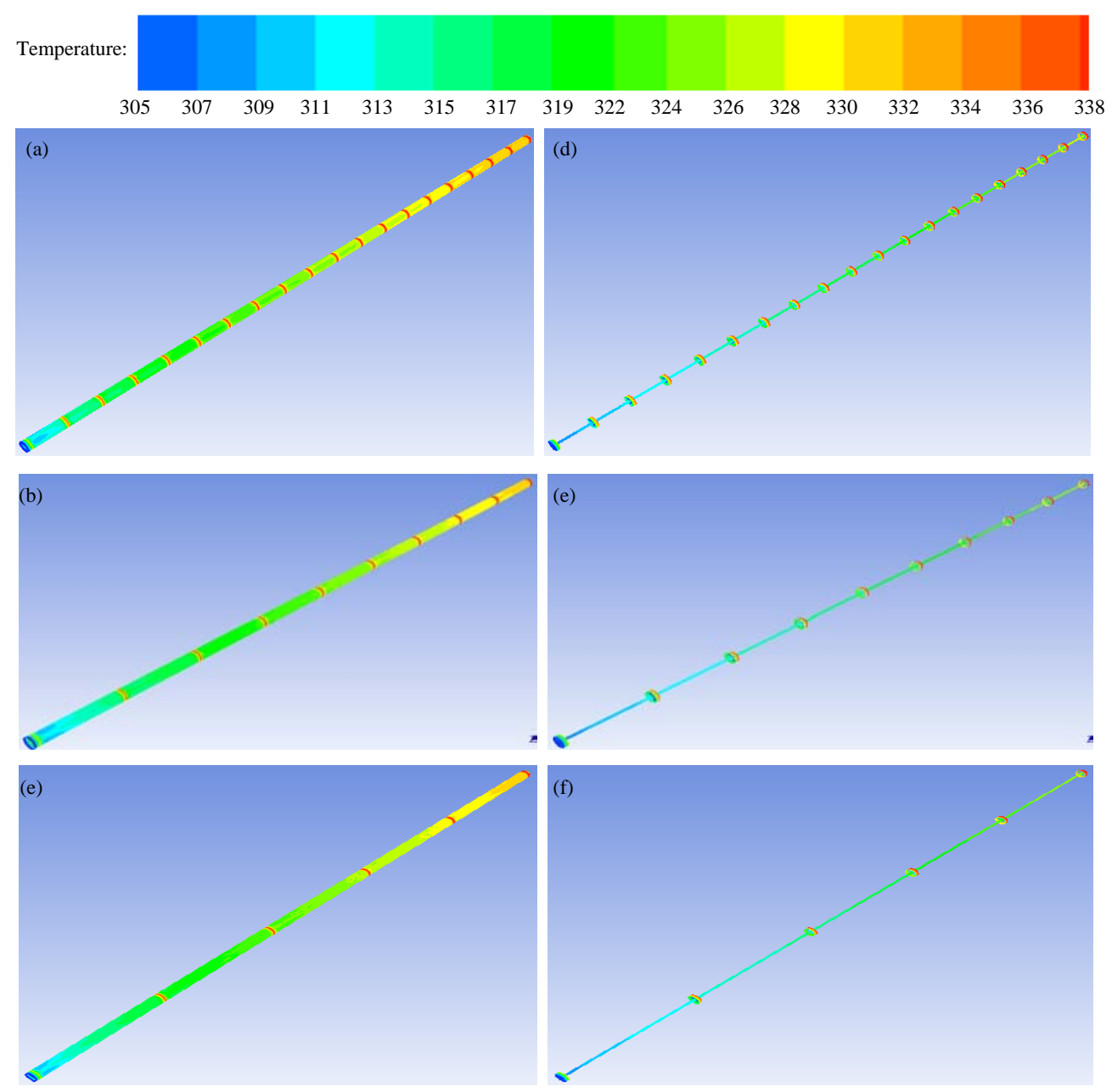

Fig. 7(a-f): Temperature contours of the fluid in the tubes at a Reynolds number (Re) of 460 (a) Tube with 20 rings (b) Tube with 10 rings (c) Tube with 6 rings (d) 20 baffle rings (e) 10 baffle rings and (f) 6 baffle rings

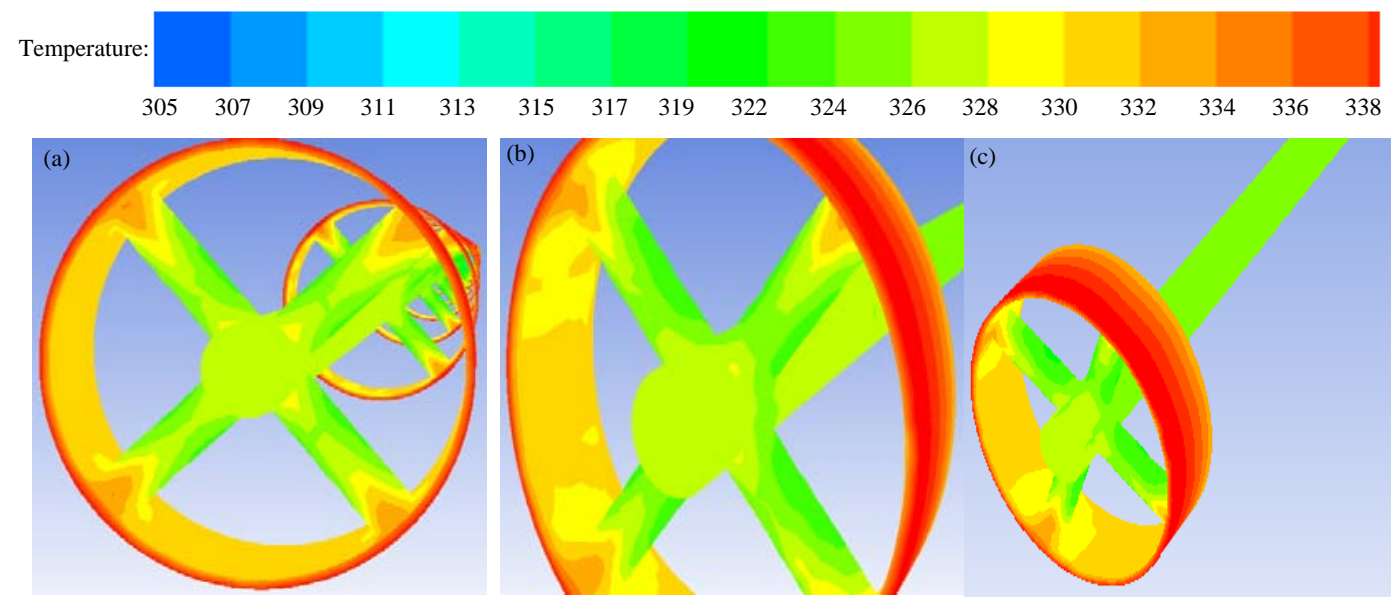

Fig. 8(a-c): Temperature contours of the fluid over the baffle structure with Re of 460 (a) 20 baffle rings (b) 10 baffle rings and (c) 6 baffle rings 


\section{CONCLUSION}

The friction factor, TEF and the Nusselt number for the receiver tube with baffles were compared with those of plain tube without baffles under similar flow conditions to determine the heat transfer enhancement. Results revealed that the temperature in the center line of flow increased by $9-14^{\circ} \mathrm{C}$ relative to the temperature in the plain tube. The correlations for the Nusselt number, friction factor and TEF were developed a PTC receiver tube equipped with artificial baffles.

\section{REFERENCES}

Abdollahi, A. and M. Shams, 2015. Optimization of shape and angle of attack of winglet vortex generator in a rectangular channel for heat transfer enhancement. Appl. Therm. Eng., 81: 376-387.

Abduhamed, A.J., N.M. Adam, A.A. Hairuddin and H.K. Kareem, 2016. Design and fabrication of a heat exchanger for portable solar water distiller system. Intl. Food Res. J., 23: 15-22.

Acır, A. and I. Ata, 2016. A study of heat transfer enhancement in a new solar air heater having circular type turbulators. J. Energy Inst., 89: 606-616.

Bergman, T.L., F.P. Incropera, D.P. DeWitt and A.S. Lavine, 2011. Fundamentals of Heat and Mass Transfer. 7th Edn., John Wiley \& Sons, Hoboken, New Jersey, USA., ISBN-13:978-0470-50197-9, Pages: 1052.

Bilen, K., U. Akyol and S. Yapici, 2001. Heat transfer and friction correlations and thermal performance analysis for a finned surface. Energy Convers. Manage., 42: 1071-1083.

Christiansen, E.B. and S.E. Craig Jr, 1962. Heat transfer to pseudoplastic fluids in laminar flow. AIChE J., 8: $154-160$.

Diwan, K. and M.S. Soni, 2015. Heat transfer enhancement in absorber tube of parabolic trough concentrators using wire-coils inserts. Univ. J. Mech. Eng., 3: 107-112.

Eiamsa-Ard, S., P. Nivesrangsan, S. Chokphoemphun and P. Promvonge, 2010. Influence of combined non-uniform wire coil and twisted tape inserts on thermal performance characteristics. Intl. Commun. Heat Mass Transfer, 37: 850-856.

Eiamsa-Ard, S., S. Rattanawong and P. Promvonge, 2009. Turbulent convection in round tube equipped with propeller type swirl generators. Intl. Commun. Heat Mass Transfer, 36: 357-364.

Gholami, A.A., M.A. Wahid and H.A. Mohammed, 2014. Heat transfer enhancement and pressure drop for fin-and-tube compact heat exchangers with wavy rectangular winglet-type vortex generators. Intl. Commun. Heat Mass Trans., 54: 132-140.
Guo, J., A. Fan, X. Zhang and W. Liu, 2011. A numerical study on heat transfer and friction factor characteristics of laminar flow in a circular tube fitted with center-cleared twisted tape. Int. J. Thermal Sci., 50: 1263-1270.

Hieber, C.A., 1982. Laminar mixed convection in an isothermal horizontal tube: Correlation of heat transfer data. Intl. J. Heat Mass Trans., 25: 1737-1746.

Kongkaitpaiboon, V., K. Nanan and S. Eiamsa-ard, 2010. Experimental investigation of convective heat transfer and pressure loss in a round tube fitted with circular-ring turbulators. Int. Commun. Heat Mass Transfer, 37: 568-574.

Li, W. and Z.Z. Feng, 2013. Laminar mixed convection of large-Prandtl-number in-tube nanofluid flow, Part II: Correlations. Intl. J. Heat Mass Trans., 65: 928-935.

Liu, P., N. Zheng, F. Shan, Z. Liu and W. Liu, 2018. An experimental and numerical study on the laminar heat transfer and flow characteristics of a circular tube fitted with multiple conical strips inserts. Intl. J. Heat Mass Trans., 117: 691-709.

Maradiya, C., J. Vadher and R. Agarwal, 2017. The heat transfer enhancement techniques and their thermal performance factor. Beni-Suef Univ. J. Basic Appl. Sci., 7: 1-21.

McKeon, B.J., C.J. Swanson, M.V. Zagarola, R.J. Donnelly and A.J. Smits, 2004. Friction factors for smooth pipe flow. J. Fluid Mech., 511: 41-44.

Naphon, P. and T. Suchana, 2011. Heat transfer enhancement and pressure drop of the horizontal concentric tube with twisted wires brush inserts. Intl. Commun. Heat Mass Trans., 38: 236-241.

Oliver, D.R., 1962. The effect of natural convection on viscous-flow heat transfer in horizontal tubes. Chem. Eng. Sci., 17: 335-350.

Oni, T.O. and M.C. Paul, 2016. CFD investigation of the impacts of variation in geometry of twisted tape on heat transfer and flow characteristics of water in tubes. Heat Transfer-Asian Res., 45: 482-498.

Rivier, M., P. Sebastian, T. Goli, G. Raffray and A. Collignan, 2015. Heat transfer enhancement of a circular tube heat exchanger fitted with an elliptic shaped turbulator designed in the context of developing countries. Appl. Therm. Eng., 81: 92101.

Sadeghi, O., H.A. Mohammed, M. Bakhtiari-Nejad and M.A. Wahid, 2016. Heat transfer and nanofluid flow characteristics through a circular tube fitted with helical tape inserts. Intl. Commun. Heat Mass Trans., 71: 234-244.

Sara, O.N., T. Pekdemir, S. Yapici and H. Ersahan, 2000. Thermal performance analysis for solid and perforated blocks attached on a flat surface in duct flow. Energy Convers. Manage., 41: 1019-1028. 
Saravanan, A., J.S. Senthilkumaar and S. Jaisankar, 2016. Performance assessment in V-trough solar water heater fitted with square and V-cut twisted tape inserts. Applied Thermal Eng., 102: 476-486.

Seemawute, P. and S. Eiamsa-Ard, 2010. Thermohydraulics of turbulent flow through a round tube by a peripherally-cut twisted tape with an alternate axis. Intl. Commun. Heat Mass Trans., 37: 652-659.

Shivalingaswamy, B.P. and G.A. Narahari, 2014. Numerical investigation of convective heat transfer and pressure loss in a round tube fitted with circularring turbulators. Intl. J. Sci. Res. Publ., 4: 1-5.

Skullong, S., C. Thianpong and P. Promvonge, 2015. Effects of rib size and arrangement on forced convective heat transfer in a solar air heater channel. Heat Mass Trans., 51: 1475-1485.
Skullong, S., P. Promvonge, C. Thianpong and N. Jayranaiwachira, 2017. Thermal behaviors in a round tube equipped with quadruple perforated-deltawinglet pairs. Appl. Therm. Eng., 115: 229-243.

Skullong, S., P. Promvonge, N. Jayranaiwachira and C. Thianpong, 2016. Experimental and numerical heat transfer investigation in a tubular heat exchanger with delta-wing tape inserts. Chem. Eng. Process. Intensification, 109: 164-177.

Webb, R.L., 1981. Performance evaluation criteria for use of enhanced heat transfer surfaces in heat exchanger design. Intl. J. Heat Mass Trans., 24: 715-726.

Zhang, Q. and L.B. Wang, 2016. Numerical study of heat transfer enhancement by rectangular winglet vortex generator pair in a channel. Adv. Mech. Eng., 8: 1-11. 